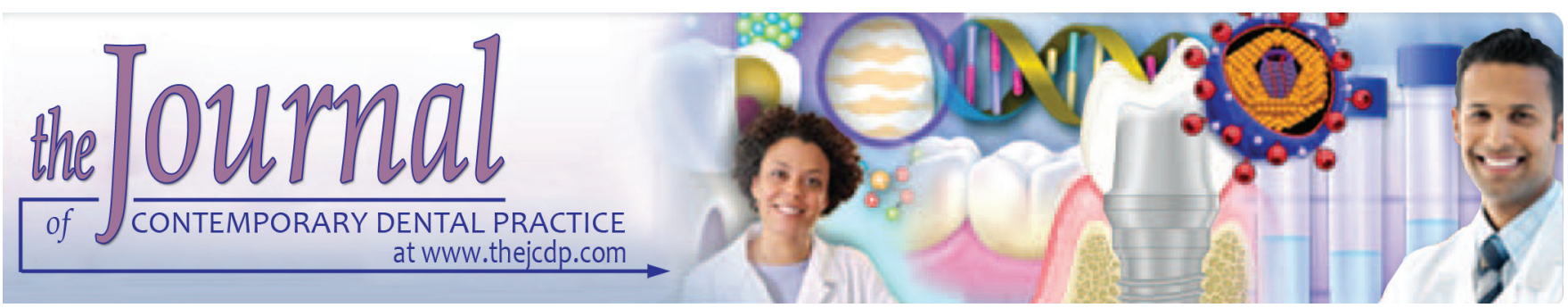

\title{
Functional Evaluation of the Behavior of Masticatory Muscles in Zygomaticomaxillary Complex Fracture: A Prospective Study
}

${ }^{1}$ Srimathi Panchanathan, ${ }^{2}$ Maya Saranathan, ${ }^{3}$ Arun Kumar Kamalakaran, ${ }^{4}$ Karthikeyan Duraisamy

\begin{abstract}
Aims: The purpose of this study is to functionally evaluate the behavior of the masticatory muscles (masseter and temporalis) following zygomaticomaxillary complex (ZMC) fractures by assessing bite force, electromyography (EMG), and mandibular movements.

Materials and methods: Group I consisted of 20 patients with unilateral ZMC fractures who were treated surgically with one-, two-, or three-point fixations at the frontozygomatic, infraorbital, or zygomaticomaxillary buttress region as per clinical and radiological assessments. Group II control group included 20 normal patients. The muscle activity was functionally evaluated before and after the surgery for a period of 6 months. The evaluation consisted of bite force measurement, EMG analysis of masseter and temporalis muscles, and measurements of mandibular movements.
\end{abstract}

Results: There was an increase in bite force and EMG activity throughout the evaluated postoperative period, but at the end of 6 months, the values were still below the control levels for majority of the patients. Maximum mouth opening increased considerably after the surgery.

Conclusion: According to bite force and EMG, the masticatory musculature returned to near normal levels by the 3rd month after the surgery.

Clinical significance: Management of fractures of the zygoma by open reduction and fixation raises the question of the location of fixation points owing to the action of masseter and temporalis on the ZMC. This study supports the current clinical concept of minimized fixation in treating $Z M C$ fractures.

Keywords: Bite force, Electromyography, Masseter, Temporalis, Zygomaticomaxillary complex fracture.

${ }^{1-4}$ Department of Oral and Maxillofacial Surgery, Government Dental Hospital and College, Chennai, Tamil Nadu, India

Corresponding Author: Maya Saranathan, Postgraduate Student (3rd Year), Department of Oral and Maxillofacial Surgery, Government Dental Hospital and College, Chennai Tamil Nadu, India, e-mail: maya.saranathan@gmail.com
How to cite this article: Panchanathan S, Saranathan M, Kamalakaran AK, Duraisamy K. Functional Evaluation of the Behavior of Masticatory Muscles in Zygomaticomaxillary Complex Fracture: A Prospective Study. J Contemp Dent Pract 2016;17(6):463-469.

Source of support: Nil

Conflict of interest: None

\section{INTRODUCTION}

Beauty of the face is defined by facial contours that are accentuated by a youthful midface configuration. The midface consists of a bony lattice with a system of relatively strong, vertically oriented struts, also called as buttress, that are thought to be a mechanical adaptation to masticatory forces. ${ }^{1}$ The zygoma is the cornerstone of the buttress system and its prominence, the malar eminence, is often the recipient of blunt trauma. Any force applied to the malar eminence or zygoma is transmitted through this series of connections in the bony lattice that comprises the midface. Starkhammar and Olofsson $(1982)^{2}$ reported that the zygomatic region is involved in $42 \%$ of facial fractures.

The integrity of zygoma is maintained by the muscles that are attached to it. Muscles that act directly on the zygoma include the masseter and anterior temporalis. ${ }^{3}$ In fracture zygoma, the masseter muscle is assumed as the primary cause of post-reduction displacement as it is capable of exerting sufficient inferiorly directed force on the fractured zygoma to cause movement, even after surgical insertion of fixation devices. ${ }^{4}$ Also, the tensile strain exerted by anterior temporalis muscle fibers at the frontozygomatic region may either displace the reduced zygomatic complex in a vertically downward direction or cause distraction osteogenesis, resulting in gradual elongation of the lateral orbital rim. ${ }^{5}$ However, 
controversy exists regarding the role of these muscles in post-reduction displacement of zygoma fractures. Hence, the purpose of this study was to evaluate the behavior of the masticatory muscles (masseter and temporalis) following zygomaticomaxillary complex (ZMC) fractures by using bite force measurements, EMG studies, and mandibular movement.

\section{MATERIALS AND METHODS}

\section{Patient Selection}

This prospective study was approved by the institution's ethical committee. Group I consisted of 20 patients (16 males and 4 females) with unilateral ZMC fracture, which was diagnosed by a palpable step in the orbital rim, zygomatic arch, or zygomatic buttress clinically and displacement of the fracture segments radiologically (digital paranasal sinus view). Inclusion criteria included dentulous patients with intact molar/premolar teeth for the purpose of measuring bite force. Bilateral fractures, comminuted fractures, fracture of other facial bones, medically compromised patients were excluded from the study. Fractures requiring reduction and fixation were identified using the classification system of Larsen and Thomsen (1968). ${ }^{6}$ All patients were treated 1 week from the day of injury. Treatment was done accordingly with one-point fixation (at zygomaticofrontal region or zygomaticomaxillary buttress), two-point fixation (zygomaticofrontal region and zygomaticomaxillary buttress) and three-point fixation (zygomaticofrontal region, zygomaticomaxillary buttress, and infraorbital rim). All the patients were evaluated 1 day prior to the surgery, and postoperatively at 1 week, 1,3 , and 6 months. Objective evaluation of the patients included bite force measurement (maximum voluntary clench measured at the bilateral molars and incisor), electromyographic study of masseter and temporalis muscles bilaterally, and mandibular movements (mouth opening,

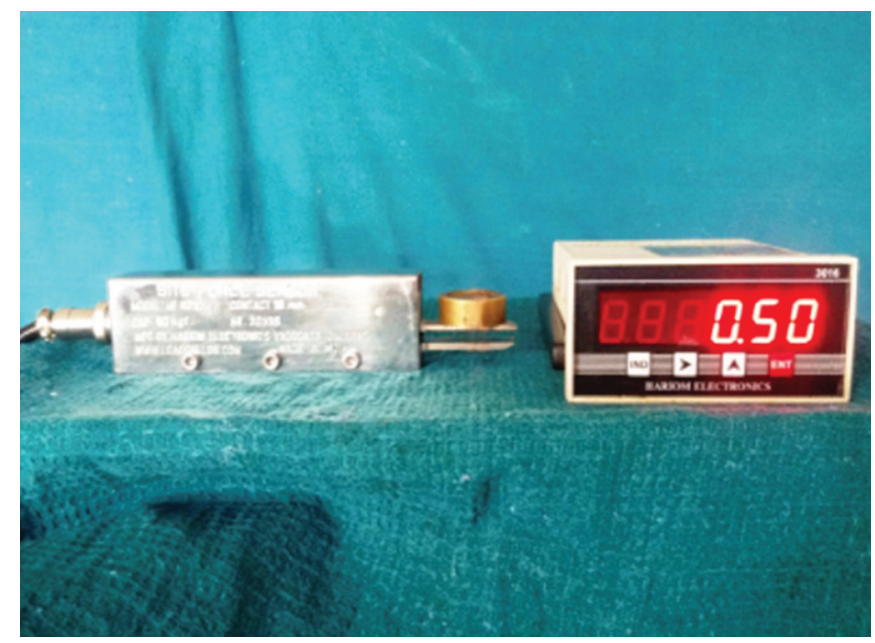

Fig. 1: Bite force apparatus right and left lateral movements and protrusion). Group II control group included 20 healthy people on whom the aforementioned parameters were evaluated.

\section{Bite Force Measurement Device}

The bite force was recorded using a strain gauge-based force transducer which can measure bite force up to $100 \mathrm{~kg}$ (100 kgf capacity). The dimension of the force sensor is $10 \mathrm{~mm}$ in height, $12 \mathrm{~mm}$ in width, and $40 \mathrm{~mm}$ in length. The force sensor is enclosed in a stainless steel casing of dimension $130 \times 39 \times 24 \mathrm{~mm}^{3}$ consisting of four strain gauges. This in turn is connected to a Wheatstone bridge circuit that converts the change in resistance into voltage. The resulting output voltage is proportional to the applied force recorded in kilogram, which can be viewed on the digital display (Fig. 1). The patient was asked to bite directly on the bite sensor three times with maximum force (maximum voluntary clench), with 2 minutes intervals between recordings. The highest value was taken as the reading for maximum voluntary clench. Evaluations were performed on the first molar (right and left) and central incisor regions (Fig. 2).

\section{Electromyogram}

Electromyography (EMG) was performed using four channels of the Aleron 401 EMG machine. The machine is set at a sweep speed of 2 to $500 \mathrm{~ms} /$ div in 13 steps sampled with a 14-bit analog digital converter. The output in millivolt $(\mathrm{mV})$ is measured as the muscle activity. Surface differential active electrodes (in red and black colors) made of solid stainless steel of $10 \mathrm{~mm}$ in diameter are placed on the designated muscle and secured with tape. Ground electrode (green color) of $30 \mathrm{~mm}$ diameter is placed on the forehead and secured with tape. Electromyographic recordings of the masseter and temporalis at rest and during maximum voluntary clench were recorded.

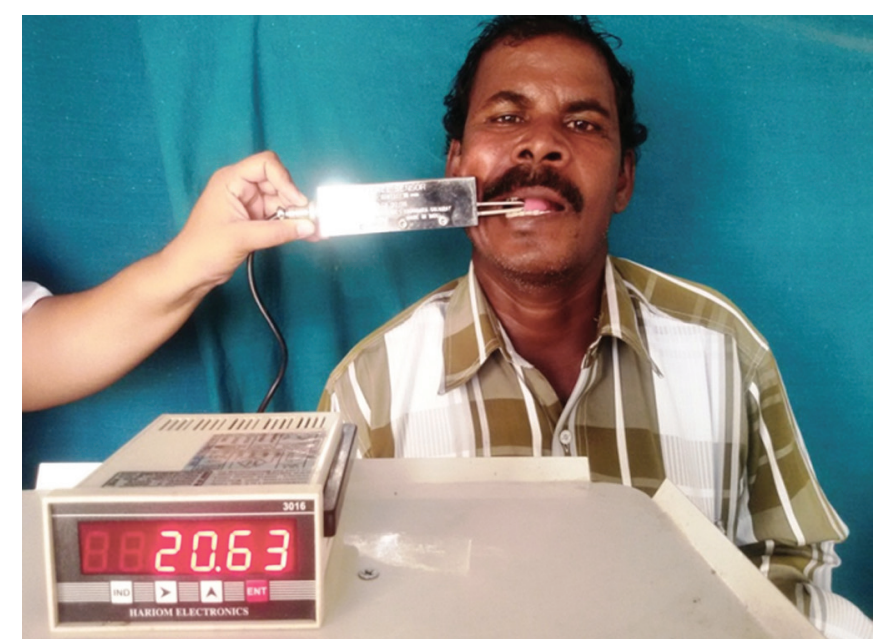

Fig. 2: Bite force measurement in right molar 


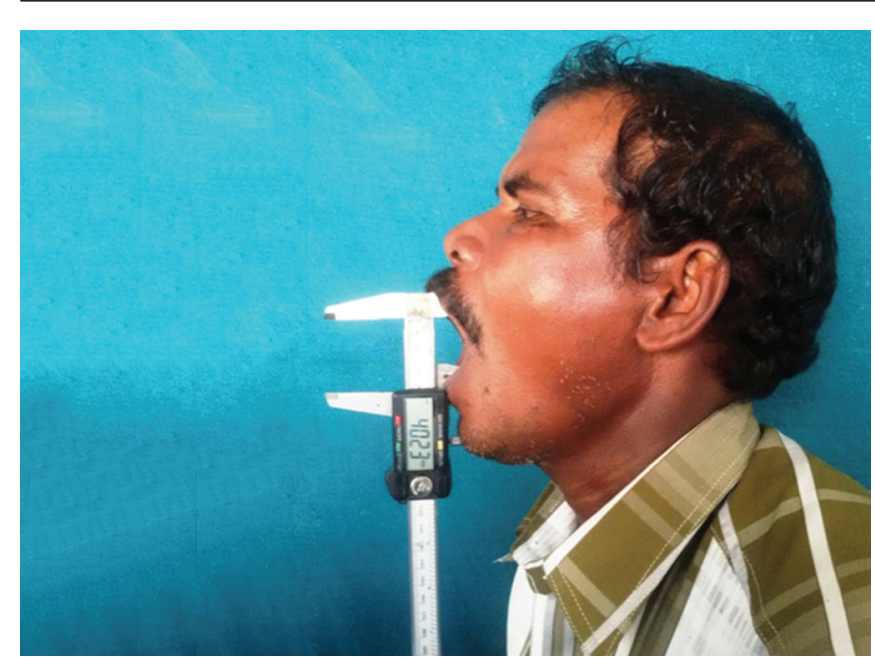

Fig. 3: Mouth opening measured using digital Vernier caliper

\section{Digital Vernier Caliper}

This precision instrument has a range of 0 to $150 \mathrm{~mm}$ and an accuracy of $\pm 0.03 \mathrm{~mm} / 0.001^{\prime \prime}$. The mandibular range of movements was measured by placing the internal jaws of the caliper on the incisal ends of the teeth. Mouth opening, right and left lateral movements, and protrusive movements were calculated (Fig. 3).

\section{Data Analyses}

Statistical analyses were performed with Statistical Package for the Social Sciences (SPSS) software version 18. Repeated measures analysis of variance (ANOVA) test was performed. A $5 \%$ level of significance $(p \leq 0.05)$ was adopted.

\section{RESULTS}

Out of the 20 fractures, 9 of them were diagnosed with right-sided ZMC fractures and 11 with left-sided ZMC fractures. The etiology was found to be road traffic accidents $(70 \%)$, assaults $(10 \%)$, and physical aggression $(20 \%)$. All the fractures were classified under group B (Larsen and Thomsen 1968) classification which required open reduction and internal fixation.

Four patients needed open reduction and internal fixation at three points, 12 patients required fixations at two points, and 4 patients required fixation at one point. Occipitomental view radiograph was taken on the 1st postoperative day and the reduction was found to be acceptable in all the 20 patients.

\section{Bite Force Measurements}

The control group (group II) used in this study presented, as an average of single measurement, the following bite force values (MVC) in the following regions: 1st molars on the right side, $43.54 \mathrm{kgf} ; 1$ st molars on the left side, $44.84 \mathrm{kgf} ;$ and incisors, $42.22 \mathrm{kgf}$.
Table 1: Bite force at maximum voluntary clench in kilogram

\begin{tabular}{lllll}
\hline $\begin{array}{l}\text { SI. } \\
\text { no. }\end{array}$ & Group I $(n=20)$ & $\begin{array}{c}\text { Right molar } \\
(\text { mean } \pm S D)\end{array}$ & $\begin{array}{l}\text { Left molar } \\
(\text { mean } \pm S D)\end{array}$ & $\begin{array}{l}\text { Incisor } \\
(\text { mean } \pm S D)\end{array}$ \\
\hline 1 & Pre-op day & $15.79 \pm 8.15^{*}$ & $15.57 \pm 7.65^{*}$ & $11.22 \pm 5.15^{*}$ \\
2 & 1-week post-op & $19.89 \pm 6.22 *$ & $17.44 \pm 6.55^{*}$ & $16.66 \pm 4.60^{*}$ \\
3 & 1-month post-op & $29.45 \pm 6.66^{*}$ & $28.78 \pm 9.09^{*}$ & $26.15 \pm 5.25^{*}$ \\
4 & 3-month post-op & $34.31 \pm 5.23$ & $34.66 \pm 6.35$ & $31.32 \pm 4.08^{*}$ \\
5 & 6-month post-op & $39.00 \pm 4.20$ & $39.05 \pm 6.06$ & $35.62 \pm 4.16^{*}$ \\
6 & Group II - Control & $43.54 \pm 7.52$ & $44.84 \pm 6.44$ & $42.22 \pm 3.16$ \\
\hline *Significance at $p \leq 0.05$ between groups I and II &
\end{tabular}

In group I patients, the maximum voluntary clench in the right and left molar region was statistically significant when compared with the control group till the 1st month postoperatively. In the incisor region, the maximum voluntary clench was statistically significant when compared with the control group till the 6th month postoperatively. There was no statistically significant difference in the bite force values between right molar, left molar, and incisors during the postoperative period (Table 1).

When comparing the pre-operative MVC to the 6-month postoperative, there was $59.5 \%$ increase in the right molar region, $60.1 \%$ increase in the left molar region, and $68.5 \%$ increase in the incisor region. When comparing the bite force of group I with the control group, the bite force in the right first molar was $45.68 \%$ than in the control group increasing to $78.8 \%$ in $3 \mathrm{rd}$ month postoperative period. For the first left molar, these values were 38.89 and $77.29 \%$ respectively, and the values for the incisors were 39.45 and $74.18 \%$ respectively.

When comparing the values of the bite force in the operated side and in the non-operated side of the group I patients, it was observed that there was no statistically significance for $\mathrm{p} \leq 0.05$.

\section{Electromyogram Measurements}

There was increase in the EMG activity of the masseter muscle throughout the evaluated postoperative period. In clenching position, when compared with the control group (group II), there was statistically significant difference in the EMG activity throughout the evaluated postoperative period of 6 months. There was no statistically significant difference noted between the right and the left masseter muscle activity. At rest position, the values of the EMG activity of the masseter approached that of the control reflecting a normal or near normal activity of the muscles. However, the difference was not statistically significant in the rest position between groups I and II. There was an overall increase in the activity of masseter throughout the postoperative period in protrusion and lateral movements, but the levels did not reach that of the control (Tables 2 and 3 ). 
Table 2: Electromyography activity (mean in millivolts) in right masseter muscle

\begin{tabular}{llllllll}
\hline & $\begin{array}{l}\text { Clenching } \\
\text { mean } \pm S D\end{array}$ & $\begin{array}{l}\text { Closing } \\
\text { mean } \pm S D\end{array}$ & $\begin{array}{l}\text { Protrusion } \\
\text { mean } \pm S D\end{array}$ & $\begin{array}{l}\text { Left lateral } \\
\text { mean } \pm S D\end{array}$ & $\begin{array}{l}\text { Right lateral } \\
\text { mean } \pm S D\end{array}$ & $\begin{array}{l}\text { Open } \\
\text { mean } \pm S D\end{array}$ & $\begin{array}{l}\text { Rest } \\
m e a n \pm S D\end{array}$ \\
\hline Preoperative & $158.80 \pm 34.39^{*}$ & $24.45 \pm 8.82^{*}$ & $43.70 \pm 13.96^{*}$ & $34.95 \pm 7.12^{*}$ & $56.10 \pm 26.45$ & $53.70 \pm 27.31^{*}$ & $18.00 \pm 4.18$ \\
1-week post-op & $184.85 \pm 30.36^{*}$ & $45.95 \pm 10.98^{*}$ & $57.30 \pm 12.32^{*}$ & $54.90 \pm 8.60^{*}$ & $70.85 \pm 17.26$ & $189.80 \pm 105.82^{*}$ & $22.65 \pm 2.96$ \\
1-month post-op & $235.00 \pm 37.77^{*}$ & $85.55 \pm 8.63$ & $83.50 \pm 10.00$ & $61.30 \pm 9.05^{*}$ & $82.80 \pm 7.93$ & $496.90 \pm 129.35$ & $23.40 \pm 2.21$ \\
3-month post-op & $280.30 \pm 34.82^{*}$ & $88.05 \pm 10.74$ & $86.15 \pm 9.65$ & $85.65 \pm 7.86$ & $89.10 \pm 9.07$ & $561.30 \pm 111.65$ & $23.90 \pm 1.77$ \\
6-month post-op & $314.10 \pm 17.03^{*}$ & $98.90 \pm 8.45$ & $121.40 \pm 13.16$ & $95.75 \pm 3.38$ & $95.20 \pm 4.66$ & $567.75 \pm 135.53$ & $24.45 \pm 1.43$ \\
Group II - Control & $580.00 \pm 151.72$ & $101.65 \pm 7.36$ & $148.25 \pm 8.03$ & $99.90 \pm 9.89$ & $97.60 \pm 14.48$ & $568.55 \pm 115.16$ & $24.65 \pm 3.99$ \\
\hline
\end{tabular}

*Significance at $p \leq 0.05$ between groups I and II

Table 3: Electromyography activity (mean in millivolts) in left masseter muscle

\begin{tabular}{llllllll}
\hline & $\begin{array}{l}\text { Clenching } \\
\text { mean } \pm S D\end{array}$ & $\begin{array}{l}\text { Closing } \\
\text { mean } \pm S D\end{array}$ & $\begin{array}{l}\text { Protrusion } \\
\text { mean } \pm S D\end{array}$ & $\begin{array}{l}\text { Left lateral } \\
\text { mean } \pm S D\end{array}$ & $\begin{array}{l}\text { Right lateral } \\
\text { mean } \pm S D\end{array}$ & $\begin{array}{l}\text { Open } \\
\text { mean } \pm S D\end{array}$ & $\begin{array}{l}\text { Rest } \\
\text { mean } \pm S D\end{array}$ \\
\hline Preoperative & $153.65 \pm 36.00^{*}$ & $25.10 \pm 9.61^{*}$ & $41.95 \pm 11.40^{*}$ & $37.35 \pm 12.53^{*}$ & $53.65 \pm 20.98^{*}$ & $37.35 \pm 26.19^{*}$ & $16.30 \pm 6.24$ \\
1-week post-op & $178.40 \pm 31.37^{*}$ & $50.15 \pm 7.16^{*}$ & $59.80 \pm 15.18^{*}$ & $57.35 \pm 14.69^{*}$ & $82.00 \pm 27.62$ & $187.2 \pm 65.50^{*}$ & $23.30 \pm 2.57$ \\
1-month post-op & $228.65 \pm 44.89^{*}$ & $85.40 \pm 8.82$ & $83.30 \pm 9.65$ & $64.35 \pm 10.78^{*}$ & $83.85 \pm 7.37$ & $444.75 \pm 127.5^{*}$ & $24.10 \pm 2.73$ \\
3-month post-op & $282.90 \pm 34.30^{*}$ & $88.25 \pm 10.17$ & $86.10 \pm 9.64$ & $85.45 \pm 7.12$ & $88.15 \pm 8.52$ & $552.9 \pm 98.37$ & $24.05 \pm 2.56$ \\
6-month post-op & $316.05 \pm 23.77^{*}$ & $95.60 \pm 6.06$ & $107.50 \pm 6.01$ & $96.55 \pm 5.79$ & $95.85 \pm 3.2$ & $571.25 \pm 65.11$ & $24.95 \pm 2.50$ \\
Group II - Control & $802.10 \pm 121.74$ & $98.1 \pm 9.21$ & $109.55 \pm 9.04$ & $93.35 \pm 8.34$ & $93.80 \pm 7.66$ & $625.35 \pm 123.69$ & $26.15 \pm 17.11$ \\
\hline
\end{tabular}

*Significance at $p \leq 0.05$ between groups I and II

The EMG activity of the temporalis muscle showed increase in values throughout the evaluated postoperative period. When compared with the control group (group II), there was statistically significant difference in the temporalis muscle activity in clenching, open, lateral, and protrusive positions throughout the evaluated postoperative period of 6 months. There was no statistically significant difference noted between the right and the left temporalis muscle activity. At rest position, the values of the EMG activity of the right and left temporalis were more than that of the control. This difference was statistically significant throughout the evaluated postoperative period of 6 months indicative of muscle activity (Tables 4 and 5).

\section{Mandibular Movements}

The mouth opening increased with time throughout the postoperative period. When compared with group II control, there was statistical significance in the values till the 1st postoperative month. Right and left lateral movement and protrusive movement increased throughout the postoperative evaluated period of 6 months. When

Table 4: Electromyography activity (mean in millivolts) of right temporalis muscle

\begin{tabular}{llllllll}
\hline & $\begin{array}{l}\text { Clenching } \\
\text { mean } \pm S D\end{array}$ & $\begin{array}{l}\text { Closing } \\
\text { mean } \pm S D\end{array}$ & $\begin{array}{l}\text { Protrusion } \\
\text { mean } \pm S D\end{array}$ & $\begin{array}{l}\text { Left lateral } \\
\text { mean } \pm S D\end{array}$ & $\begin{array}{l}\text { Right lateral } \\
\text { mean } \pm S D\end{array}$ & $\begin{array}{l}\text { Open } \\
\text { mean } \pm S D\end{array}$ & $\begin{array}{l}\text { Rest } \\
\text { mean } \pm S D\end{array}$ \\
\hline Preoperative & $155.80 \pm 26.28^{*}$ & $24.70 \pm 10.48^{*}$ & $46.35 \pm 18.54^{*}$ & $52.35 \pm 13.17$ & $50.50 \pm 18.65$ & $54.45 \pm 16.42^{*}$ & $22.00 \pm 3.88$ \\
1-week post-op & $179.40 \pm 20.78^{*}$ & $50.55 \pm 6.57^{*}$ & $68.80 \pm 17.80^{*}$ & $81.35 \pm 12.26^{*}$ & $60.95 \pm 13.73$ & $90.00 \pm 13.44^{*}$ & $24.00 \pm 2.44^{*}$ \\
1-month post-op & $194.30 \pm 39.10^{*}$ & $84.85 \pm 8.29^{*}$ & $83.95 \pm 7.82^{*}$ & $83.95 \pm 7.89^{*}$ & $86.75 \pm 8.07$ & $128.10 \pm 37.45^{*}$ & $23.45 \pm 2.06^{*}$ \\
3-month post-op & $265.70 \pm 28.44^{*}$ & $89.20 \pm 10.37^{*}$ & $85.10 \pm 8.30^{*}$ & $84.75 \pm 10.27^{*}$ & $85.70 \pm 8.78^{*}$ & $173.20 \pm 42.18^{*}$ & $23.65 \pm 2.41^{*}$ \\
6-month post-op & $296.30 \pm 20.33^{*}$ & $95.00 \pm 4.25^{*}$ & $99.10 \pm 4.41^{*}$ & $95.00 \pm 4.49^{*}$ & $96.15 \pm 3.57^{*}$ & $218.65 \pm 32.69^{*}$ & $23.55 \pm 2.25^{*}$ \\
Group II - Control & $521.45 \pm 142.87$ & $263.00 \pm 99.56$ & $349.60 \pm 118.00$ & $60.20 \pm 8.76$ & $60.20 \pm 9.45$ & $523.80 \pm 79.09$ & $18.05 \pm 4.9$ \\
\hline
\end{tabular}

*Significance at $\mathrm{p} \leq 0.05$ between groups I and II

Table 5: Electromyography activity (mean in millivolts) of left temporalis muscle

\begin{tabular}{llllllll}
\hline & $\begin{array}{l}\text { Clenching } \\
\text { mean } \pm S D\end{array}$ & $\begin{array}{l}\text { Closing } \\
\text { mean } \pm S D\end{array}$ & $\begin{array}{l}\text { Protrusion } \\
\text { mean } \pm S D\end{array}$ & $\begin{array}{l}\text { Left lateral } \\
\text { mean } \pm S D\end{array}$ & $\begin{array}{l}\text { Right lateral } \\
\text { mean } \pm S D\end{array}$ & $\begin{array}{l}\text { Open } \\
\text { mean } \pm S D\end{array}$ & $\begin{array}{l}\text { Rest } \\
m e a n \pm S D\end{array}$ \\
\hline Preoperative & $145.65 \pm 25.20^{*}$ & $28.11 \pm 9.36^{*}$ & $41.80 \pm 7.32^{*}$ & $54.95 \pm 11.49^{*}$ & $54.45 \pm 15.23^{*}$ & $55.25 \pm 20.64^{*}$ & $18.55 \pm 5.22$ \\
1-week post-op & $178.05 \pm 25.32^{*}$ & $51.47 \pm 7.12^{*}$ & $55.40 \pm 5.81^{*}$ & $77.65 \pm 12.22$ & $64.60 \pm 15.62$ & $61.10 \pm 15.72^{*}$ & $24.6 \pm 4.5^{*}$ \\
1-month post-op & $216.40 \pm 43.30^{*}$ & $82.95 \pm 6.67^{*}$ & $91.80 \pm 10.71^{*}$ & $82.95 \pm 11.43$ & $78.95 \pm 10.80$ & $155.55 \pm 16.24^{*}$ & $23.5 \pm 1.93^{*}$ \\
3-month post-op & $288.70 \pm 20.74^{*}$ & $89.21 \pm 9.61^{*}$ & $89.40 \pm 8.67^{*}$ & $84.80 \pm 7.51$ & $85.50 \pm 7.55$ & $163.15 \pm 30.66^{*}$ & $23.85 \pm 2.39^{*}$ \\
6-month post-op & $316.20 \pm 20.60^{*}$ & $97.95 \pm 4.98^{*}$ & $100.40 \pm 6.02^{*}$ & $94.55 \pm 2.89$ & $96.30 \pm 6.12$ & $194.90 \pm 31.29^{*}$ & $26.05 \pm 3.08^{*}$ \\
Group II - Control & $733.90 \pm 73.86$ & $697.84 \pm 141.46$ & $649.00 \pm 97.92$ & $71.70 \pm 12.70$ & $69.80 \pm 5.58$ & $737.50 \pm 37.65$ & $16.25 \pm 3.89$ \\
\hline
\end{tabular}

*Significance at $p \leq 0.05$ between groups I and II 
Table 6: Mandibular movements

\begin{tabular}{lllll}
\hline$n=20$ & $\begin{array}{l}\text { Mouth opening } \\
\text { mean } \pm S D\end{array}$ & $\begin{array}{l}\text { Right lateral movement } \\
\text { mean } \pm S D\end{array}$ & $\begin{array}{l}\text { Left lateral movement } \\
\text { mean } \pm S D\end{array}$ & $\begin{array}{l}\text { Protrusion } \\
\text { mean } \pm S D\end{array}$ \\
\hline Preoperative & $29.68 \pm 5.05^{*}$ & $5.86 \pm 1.53^{*}$ & $5.95 \pm 1.78^{*}$ & $2.54 \pm 1.00^{*}$ \\
1-week post-op & $36.84 \pm 5.51^{*}$ & $6.31 \pm 1.32^{*}$ & $6.28 \pm 1.46^{*}$ & $3.00 \pm 0.82^{*}$ \\
1-month post-op & $39.92 \pm 4.47^{*}$ & $7.04 \pm 1.14^{*}$ & $6.88 \pm 1.30^{*}$ & $3.32 \pm 0.73$ \\
3-month post-op & $41.92 \pm 3.58$ & $7.78 \pm 0.96$ & $7.51 \pm 0.96$ & $3.54 \pm 0.72$ \\
6-month post-op & $44.28 \pm 2.53$ & $8.62 \pm 0.9$ & $8.37 \pm 0.84$ & $3.96 \pm 0.43$ \\
Group II - Control & $45.56 \pm 3.18$ & $8.63 \pm 1.34$ & $8.61 \pm 1.51$ & $4.00 \pm 1.12$ \\
\hline
\end{tabular}

*Significance at $p \leq 0.05$ between groups I and II

compared to group II controls, there was statistical significance till the 1st postoperative month for lateral movements and till 1st postoperative week for protrusive movements. However, the mandibular movements returned to near normal levels after the 1st postoperative month (Table 6).

\section{DISCUSSION}

The four salient considerations in treating ZMC fractures are proper reduction, adequate stabilization, adequate orbital reconstruction (when necessary), and adequate handling/positioning of periorbital soft tissues. ${ }^{7}$ The most important principle in treating these fractures is the adequacy of reduction without which the stabilization is weak. The aim of surgically exposing the fracture site for open reduction and internal fixation is to adequately restore the loss of anatomical configuration, bring about habitual function, and prevent the late visual disorders and cosmetic deformities. ${ }^{8}$

Zingg et $\mathrm{al}^{9}$ reviewed $946 \mathrm{ZMC}$ fractures treated by a variety of means, including 164 treated by closed reduction, and found a $13 \%$ incidence of malar asymmetry. Hence, the need for aggressive surgical procedures of ZMC fracture treatment through open reduction with 3 to 4 points exposure has been put forward for accurate reduction. ${ }^{10}$ According to Fain et $\mathrm{al}^{8}$ and Manson et $\mathrm{al}^{11}$ fixation is essential to prevent rotation of the zygomatic bone, and the stability can be achieved both with plates and screws, in one or two points, with no need for fixing it in three or four points, other than in cases of comminuted fractures.

Some studies show that the instability of ZMC fracture is directly due to the masseter muscle action, and indirectly the temporal muscles. ${ }^{12}$ However, Ellis and Kittidumkerng ${ }^{7}$ evaluated 22 patients clinically and radiographically after ZMC fracture surgeries and showed that the existence of ill-positioned zygomatic bone was probably because these fractures were not adequately reduced during surgery and was not related to masseter muscle action.

In the present study, the intraoperative assessment of the stability of the repositioned ZMC was determined using digital pressure after reduction to determine the need for applying fixation devices. ${ }^{9}$ The present study is in agreement with the study by Dal Santo et $\mathrm{al}^{4}$, wherein there was no further worsening of the facial asymmetry in the postoperative period, i.e., the modicum of symmetry achieved intraoperatively sustained throughout the postoperative period of 6 months.

Assessment of the biting force (maximum voluntary clench) is a direct measure of the function of masseter attached to the zygoma and to a certain extent, the measure of the strain that indirectly develops in the temporalis muscle due to this action. The present study showed that the differences in the values of the bite force and electromyographic activities, in the operated side and in the non-operated side of the group I patients, were not statistically significant for $\mathrm{p} \leq 0.05$. Also, the stability obtained by fixation (one-, two-, or three-point fixation) showed no statistically significant intragroup variance $(p \leq 0.05)$. This is consistent with the findings of Ellis and Kittidumkerng ${ }^{7}$ where regardless of the number of fixation devices applied, there was no radiologic evidence of post-reduction displacement. The results of Dal Santo et al show similar findings wherein after fracture, the masseter force slowly increases, but at 4 weeks after surgery, most patients were still well below the control levels.

In the present study, bite force in the molar region was less in patients with ZMC fracture and was $36.26 \%$ of the control group. Four weeks after fracture, the values were less than that of control (45.68\%). This difference was statistical significant till the 3rd postoperative month. At the 6th postoperative month period, the bite force was $89.57 \%$ of the control group. These results are in agreement with the findings of Ribeiro et $\mathrm{al}^{13}$ in which bite force in the region of first molars was close to $70 \%$ of the control group values.

The EMG activities measured during various functional movements assess the capacity of the muscle to reinforce motor units for facilitating these functions. Following a fracture, the muscles lose their anatomical relation with the facial skeleton and can undergo spasm even at rest position, which is in contrast to uninjured 
muscle (non-fractured) where there are no spasms at rest. On analyzing the EMG data, the present study showed that at 1 week postoperative period, the masseter muscles presented an $8 \%$ increase in EMG activity compared with control in the right masseter and $10.8 \%$ increase in left masseter activity. In the temporal muscles, there was $32.96 \%$ increase in EMG activity in right temporalis and $16.70 \%$ increase in left temporalis muscle activity than the control. This is in contrast to the study by Ribeiro et $\mathrm{al}^{13}$ where the EMG data during rest for the group with a fractured ZMC are: The masseter muscles presented a $30 \%$ increase in EMG activity compared with the control for the right masseter, and a $2.1 \%$ increase for the left masseter, and the temporal muscles showed a $31.7 \%$ higher activation for the right temporal muscle and 38.3\% for the left. In general, the present study showed that the EMG activity for functional movements in group I was found to be less throughout the postoperative period when compared to the control group. But there was an increase in the EMG activity in the group I throughout the evaluated postoperative period. This was consistent with the findings of Dal Santo et $\mathrm{al}^{4}$ and Ribeiro et al. ${ }^{13}$

This increase in the EMG activity of the temporalis muscle in fracture ZMC may be indicative of stomatogathic system dysfunction. ${ }^{14}$ This is in accordance to the study by Oyen and Tsay ${ }^{15}$ that there is transmission of greater forces to the region of the frontal process of the zygoma, with these forces being twofold greater on the working side compared with the balance side during mandible lateral movements. Also, Stassen et $\mathrm{al}^{16}$ concluded that functional forces exerted by the temporalis muscle may cause delayed postoperative distraction at the frontozygomatic suture. Hence it can be safely assumed that there is more muscle activity at the frontozygomatic area and therefore it requires fixation to prevent post reduction displacement.

Furthermore, the need for fixation at the frontozygomatic area has been advocated in many studies. 7,17 Champy et $\mathrm{al}^{18}$ used a single bone plate at the frontozygomatic area in 342 isolated ZMC fractures and found that only $6(1.8 \%)$ had unsatisfactory results. Similarly, Chuong and Kaban ${ }^{19}$ showed that rotational tendency after reduction necessitates at least one-point fixation, usually at the zygomaticofrontal suture. This is in line with the philosophy popularized by Manson et $\mathrm{al}^{1}$ that the zygomaticofrontal suture is the best fixation point, but it cannot be used as a single reference guide for alignment.

However, one must keep in mind that zygomaticomaxillary buttress provides a great mechanical advantage for fixation as it can prevent medial rotation of the ZMC into the maxillary sinus, provided it is not severely comminuted. It acts as a direct antagonist to the action of traction provoked by the masseter muscle. ${ }^{20}$ The fixation of the zygomaticomaxillary buttress may be indicated to give the proper anterior projection of the $\mathrm{ZMC}$ in cases of unstable or complex $\mathrm{ZMC}$ fracture and can also be used as a measure for proper alignment while the greater wing of the sphenoid is a key area in determining the final result for alignment. ${ }^{1,9}$

Hence fixation at the frontozygomatic or in the frontozygomatic buttress region is sufficient for stabilization of most ZMC fractures. This is in line with the minimization concept currently followed in the clinical practice, wherein three-dimensional stability in quadripod zygomatic fracture can be satisfactorily obtained with two-point fixation or one-point fixation, provided there is no gross comminution or displacement wherein two/ one point will not provide adequate stability. ${ }^{21}$

\section{CONCLUSION}

The bite force measurements and EMG activity predict the functional behavior of the muscles and give a picture of when these muscle activities return to normal/nearnormal limits. This provides a rationale for the location of the fixation points that will best maintain the position of the reduced fractures during the healing period. This in turn decreases patient morbidity by decreasing the operative time and eliminates the need for multiple incisions for access and vision. However, further studies with larger samples, standardized treatment protocol, utilization of minimum variables, and standardized radiological protocol for outcome assessment are recommended to verify and confirm the pattern of recovery of the masticatory muscle evaluated in this study.

\section{CLINICAL SIGNIFICANCE}

The present study supports the concept of minimization of fixation after assessing bite force, EMG activity, and mandibular movements, the prime parameters defining the possible role of masticator muscles exerting displacing forces in a fractured zygoma. The bite force and EMG studies suggest that the muscle activity returns to near normal levels after the 1st postoperative month, though the values are less than that of the control. This negates the hypothesis that masseter is a cause for postreduction displacement of zygoma fractures. This is further corroborated by no postoperative worsening of facial symmetry and the return of habitual mandibular function within 1st postoperative month. Hence fixation at frontozygomatic suture site is mandatory and zygomaticomaxillary buttress is to be used as a reference point to align the fractured segments in most of the zygoma fractures. Infraorbital rim fixation is undertaken only in gross fractures involving infraorbital rim and orbital floor. 


\section{REFERENCES}

1. Manson PN, Hoopes JE, Su CT. Structural pillars of the facial skeleton: an approach to the management of Le Fort fractures. Plast Reconstr Surg 1980 Jul;66(1):54-62.

2. Starkhammar H, Olofsson J. Facial fractures: a review of 922 cases with special reference to incidence and aetiology. Clin Otolaryngol 1982;7(6):405-409.

3. Haskell R. Applied surgical anatomy. In: Williams JL, editor. Rowe and Williams maxillofacial injuries. New York (NY): Churchill Livingstone; 1994. p. 19-23.

4. Dal Santo F, Ellis E, Throckmorton GS. The effects of zygomatic complex fracture on masseteric muscle force. J Oral Maxillofac Surg 1992 Aug;50(8):791-799.

5. Oyen OJ, Melugin MB, Indresano AT. Strain gauge analysis of the frontozygomatic region of the zygomatic complex. J Oral Maxillofac Surg 1996 Sep;54(9):1092-1095.

6. Larsen OD, Thompson M. Zygomatic fractures: a simplified classification for practical use. Scand J Plast Reconstr Surg 1978;12(1):55-58.

7. Ellis E 3rd, Kittidumkerng W. Analysis of treatment for isolated zygomaticomaxillary complex fractures. Oral Maxillofac Surg 1996 Apr;54(4):386-400.

8. Fain J, Peri G, Verge P, Thevonen D. The use of a single frontozygomatic osteosynthesis plate and a sinus balloon in the repair of fractures of the lateral middle third of the face. J Oral Maxillofac Surg 1981 Aug;9(3):188-193.

9. Zingg M, Laedrach K, Chen J, Chowdhury K, Vuillemin T, Sutter F, Raveh J. Classification and treatment of zygomatic fractures. J Oral Maxillofac Surg 1992 Aug;50(8):778-790.

10. Karlan MS, Cassisi NJ. Fractures of the zygoma. A geometric, biomechanical, and surgical analysis. Arch Otolaryngol 1979 Jun;105(6):320-327.

11. Manson PN, Ruas E, Iliff N, Yaremchuk M. Single eyelid incision for exposure of the zygomatic bone and orbital reconstruction. Plast Reconstr Surg 1987 Jan;79(1):120-126.
12. Rinehart GC, Marsh JL. Internal fixation of malar fractures: an experimental biophysical study. Plast Reconstr Surg 1989 Jul;84(1):21-25.

13. Ribeiro MC, Regalo SC, Pepato AO, Siéssere S, de Souza LG, Sverzut CE, Trivellato AE. Bite force, electromyography, and mandible mobility during the 6-month period after surgical treatment for isolated fractures of the zygomatico-orbital complex. Oral Surg Oral Med Oral Pathol Oral Radiol Endod 2011 Apr;111(4):e1-e7.

14. Silva MA, Issa JP, Vitti M, Silva AM, Semprini M, Regalo SC. Electromyographical analysis of the masseter muscle in dentulous and partially toothless patients with temporomandibular joint disorders. Electromyogr Clin Neurophysiol 2006 Sep;46(5):263-268.

15. Oyen OJ, Tsay TP. A biomechanical analysis of craniofacial form and bite force. Am J Orthod Dentofacial Orthop 1991 Apr;99(4):298-309.

16. Stassen LF, Kerawala C. Peri- and intraorbital trauma and orbital reconstruction. In: Ward Booth P, Schendel SA, Hausamen JE, editors. Maxillofacial surgery. London: Churchill Livingstone; 1999. p. 177-193.

17. Covington DS, Wain Wright DJ. Changing patterns in the epidemiology and treatment of zygoma fractures: 10-year review. J Trauma 1994 Aug;37(2):243-248.

18. Champy M, Gerlach KL, Kahn JL, Pape H-D. Treatment of zygomatic bone fractures. In: Hjorting-Hansen E, editor. Oral and maxillofacial surgery: proceedings from the 8 th international conference of oral and maxillofacial surgery. Chicago (IL): Quintessence; 1985. p. 226-231.

19. Chuong R, Kaban L. Fractures of the zygomatic complex. J Oral Maxillofac Surg 1986;44:283-288.

20. Gruss JS, Mackinnon SE. Complex maxillary fractures: role of buttress reconstruction and immediate bone grafts. Plast Reconstr Surg 1986 Jul;78(1):9-22.

21. Kovacs AF, Ghahremani M. Minimization of zygomatic complex fracture treatment. Int J Oral Maxillofac Surg 2001 Oct;30(5):380-383. 